\title{
Role of imprint cytology and frozen section in the diagnosis of tumours
}

\author{
Shubha. H.V. ${ }^{1}$, Arun. H.N. ${ }^{2}$, Nirmala. C. ${ }^{3}$, Dayananda B.S. ${ }^{4}$ \\ ${ }^{1}$ Dr. Shubha. H.V., Assistant Professor, Department of Pathology, Sapthagiri Institute of Medical Sciences and Research \\ Centre, Chikkasandra, Bangalore. ${ }^{2}$ Dr. Arun. H. N., Surgical Oncologist, Department of Surgery, Bangalore Medical \\ College and Research Institute, Bangalore, Karnataka, ${ }^{3}$ Dr. Nirmala. C., Professor, Department of Pathology, Bangalore \\ Medical College and Research Institute, Bangalore, ${ }^{4}$ Dr. Dayananda. S. Biligi, Professor and Head of the Department, \\ Department of Pathology, Bangalore Medical College and Research Institute, Bangalore, Karnataka, India.
}

Corresponding Author: Dr. Shubha. H.V., Assistant Professor, Department of Pathology, Sapthagiri Institute of Medical Sciences and Research Centre, Chikkasandra, Bangalore, India. E-mail id: drshubhahv@gmail.com

\begin{abstract}
Introduction: Imprint cytology is an economical, simple and quick method with excellent cytological clarity but cannot provide information on the depth of invasion. Frozen section is the standard method of intraoperative diagnosis but is limited by its cost, need of qualified technical staff and the freezing arte facts. Thus, both the techniques have their own limitations and combining these techniques helps in achieving high diagnostic accuracy rates. Aims: 1. To assess the combined role of imprint cytology and frozen section in the diagnosis of tumours of various organs. 2. To compare the diagnostic accuracy of imprint cytology and frozen section individually with that of the histopathological diagnosis. Materials and Methods: The present study was done in the pathology department of Bangalore medical college and research institute for a period of one year. A total of 50 surgical specimens from various organs were studied using imprint cytology and frozen section. The results of both the techniques were compared with the gold standard histopathological diagnosis. Results: Out of 50 cases, majority were ovarian neoplasms comprising of 21 (42\%) cases followed by thyroid $(14 \%)$, breast $(12 \%)$ and salivary gland $(10 \%)$ neoplasms. The majority of the cases were malignant $(50 \%)$ followed by beingn $(40 \%)$, borderline $(6 \%)$ and metastatic $(4 \%)$. The overall diagnostic accuracy of imprint cytology and frozen section in various organs were $94 \%$ and $98 \%$ respectively. The combined diagnostic accuracy was 98\%. Conclusion: Imprint cytology and frozen sections are interdependable intraoperative diagnostic modalities. Imprint cytology alone may not be able to provide a correct diagnosis. Thus, a combination of imprint cytology and frozen section helps in achieving high diagnostic accuracy rates and in distinguishing benign and malignant lesions.
\end{abstract}

Keywords: Frozen section, Imprint cytology, Intraoperative cytology

\section{Introduction}

History of scrape cytology can be tracked back to 1927 when Leonard S. Dudgeon and Vincent Patrick at the University of London raised the horizons of the rapid cytological diagnosis of freshly cut specimens with reliable accuracy rates [1,2]. Imprints prepared from fresh surgical specimens give excellent cytological clarity. It provides valuable information when frozen section interpretation is equivocal [3]. The method is simple, rapid, inexpensive and does not require special techniques or instruments [4,5]. It does not alter the utility of the specimen for subsequent histopathological examination [6]. The limitation of imprint cytology is its inability to distinguish in-situ from infiltrating carcinomas and to evaluate the depth the invasion.

Manuscript received: $4^{\text {th }}$ December 2018

Reviewed: $15^{\text {th }}$ December 2018

Author Corrected: $21^{\text {st }}$ December 2018

Accepted for Publication: $26^{\text {th }}$ December 2018
Also, it gives poor cellular yield in cases with extensive fibrosis and poses difficulty in the diagnosis. The frozen section method was standardized in 1905 by Dr. Louis B Wilson. It is the standard method for intraoperative diagnosis of tumours and provides information on the depth of infiltration but is limited by its cost, the need for qualified technical staff and the unavoidable freezing arte facts $[7,8]$.

Thus, a combination of imprint cytology and frozen section helps in achieving high diagnostic accuracy rates and in distinguishing benign and malignant lesions.

\section{Materials and Methods}

Place of study: Pathology department of Bangalore Medical College and Research Institute. 


\section{Original Research Article}

Duration of study: One year (February 2016- February 2017)

Type of study: Prospective study

Sample size: 50

\section{Inclusion criteria}

1. All the surgically resected specimens with suspected neoplastic lesion from various organs.

2. Fresh specimens submitted in clean, airtight and properly labelled containers.

3. Cases with prior information/appointment.

\section{Exclusion criteria}

1. Cases with known inflammatory and/or infectious conditions.

2. Specimens sent in formalin, water or saline.

3. Specimens sent in unlabelled containers.

Sample collection method: Ethical committee clearance was obtained from the institution. The fresh unfixed specimens were sent in clean, airtight and properly labelled containers along with the requisition forms. The clinical and radiological details were obtained by good communication with the operating surgeon.

Prior appointment for frozen sections was usually taken at least one day before by various departments.
The specimens were grossly examined by inspection and palpation. The specimen was then dissected with a sharp scalpel into two halves. The cut surface was examined for the presence of any tumour. The representative areas were selected and clean glass slides were placed on them for taking the imprint smears. Depending upon the type and consistency of the tissue, touch imprints, scrape or crush techniques were used to prepare the smears. Slides were immediately fixed in 95\% alcohol and stained with haematoxylin and eosin stain. Air dried smears were stained with Leishman's stain.

Simultaneously, bits from the representative areas were taken for frozen section examination. The tissue was embedded in OCT (Optimal Cutting Temperature) compound and sectioning was done using the Leica CM1850UV cryostat followed by rapid haematoxylin and eosin staining. The remaining tissue was fixed in $10 \%$ neutral buffered formalin for routine histopathological processing. The results were interpreted on microscopic examination and the data was entered in the excel sheet. The results of imprint cytology and frozen section were compared with that of the gold standard histopathological diagnoses.

Statistical tool: The data was analysed using the Microsoft Excel 2007 and IBM SPSS statistical analysis.

\section{Results}

A total of 50 surgically resected specimens from various organs were included in our study. The tumours were broadly classified into benign, borderline, malignant and metastatic. The majority of the cases were malignant $(50 \%)$ followed by beingn (40\%), borderline (6\%) and metastatic (4\%) (Table 1).

The overall diagnostic accuracy rate of imprint cytology in various organs was $94 \%$ and that of frozen section was $98 \%$ (Table 3 and 4). The combined diagnostic accuracy rate was $98 \%$. The false-negative and false-positive rates of imprint cytology were $4 \%$ and $2 \%$ respectively. The false negative rate of frozen section was $2 \%$. Out of three discordant cases in imprint cytology, two were due to misinterpretation error and one was due to gross sampling error.

In two of the misinterpreted cases, frozen section was helpful to arrive at the final diagnosis and in distinguishing between the benign, borderline and malignant cases. The diagnostic accuracy of imprint cytology and frozen section for malignant tumours were $96 \%$ and $98 \%$ respectively.

Table-1: Classification of the tumours into various categories in different organs

\begin{tabular}{|c|c|c|}
\hline Category & Number of cases & Percentage \\
\hline Benign & 20 & 40 \\
\hline Borderline & 03 & 06 \\
\hline Malignant & 25 & 50 \\
\hline Metastatic & 02 & 04 \\
\hline Total & $\mathbf{5 0}$ & $\mathbf{1 0 0}$ \\
\hline
\end{tabular}

Pathology Update: Tropical Journal of Pathology \& Microbiology Available online at: www.pathologyreview.in 579 | P a g e 


\section{Original Research Article}

Table-2: Organ-wise distribution of the cases diagnosed by histopathological examination.

\begin{tabular}{|c|c|c|c|c|c|}
\hline Sl. No & Organ & Histopathological diagnosis & $\begin{array}{l}\text { No. of } \\
\text { cases }\end{array}$ & $\begin{array}{c}\text { Organ } \\
\text { wise total }\end{array}$ & Percentage \\
\hline \multirow{3}{*}{1.} & \multirow{3}{*}{ Brain } & a) Pilocytic astrocytoma-WHO grade- I & 01 & \multirow{3}{*}{03} & \multirow{3}{*}{$6 \%$} \\
\hline & & $\begin{array}{l}\text { b) Glioblastoma multiforme-WHO } \\
\text { grade-IV }\end{array}$ & 01 & & \\
\hline & & c) Metastatic adenocarcinoma & 01 & & \\
\hline 2. & Pituitary gland & Pituitary adenoma & 01 & 01 & $2 \%$ \\
\hline \multirow{3}{*}{3.} & \multirow{3}{*}{ Salivary gland } & a) Pleomorphic adenoma & 03 & \multirow{3}{*}{05} & \multirow{3}{*}{$10 \%$} \\
\hline & & b) Warthin's tumour & 01 & & \\
\hline & & c) Adenoid cystic carcinoma & 01 & & \\
\hline \multirow{2}{*}{4.} & \multirow{2}{*}{ Thyroid } & a) Follicular adenoma & 02 & \multirow{2}{*}{07} & \multirow{2}{*}{$14 \%$} \\
\hline & & b) Papillary thyroid carcinoma & 05 & & \\
\hline \multirow{2}{*}{5.} & \multirow{2}{*}{ Breast } & a) Infiltrating ductal carcinoma & 05 & \multirow{2}{*}{06} & \multirow{2}{*}{$12 \%$} \\
\hline & & b) Infiltrating lobular carcinoma & 01 & & \\
\hline 6. & Stomach & $\begin{array}{l}\text { Malignant Gastrointestinal stromal } \\
\text { tumour (GIST)-Epithelioid variant }\end{array}$ & 01 & 01 & $2 \%$ \\
\hline 7. & Lung & Papillary adenocarcinoma & 01 & 01 & $2 \%$ \\
\hline \multirow[b]{2}{*}{8.} & \multirow[b]{2}{*}{ Pancreas } & a) Pancreatic adenocarcinoma & 01 & \multirow[b]{2}{*}{02} & \multirow[b]{2}{*}{$4 \%$} \\
\hline & & $\begin{array}{l}\text { b) Pancreatic Neuroendocrine } \\
\text { carcinoma }\end{array}$ & 01 & & \\
\hline \multirow{7}{*}{9.} & \multirow{7}{*}{ Ovary } & a) Benign serous cystadenoma & 06 & \multirow{7}{*}{21} & \multirow{7}{*}{$42 \%$} \\
\hline & & b) Benignmucinous cystadenoma & 05 & & \\
\hline & & c) Borderline mucinoustumour & 03 & & \\
\hline & & d) Serous papillarycystadenocarcinoma & 04 & & \\
\hline & & e) Sclerosing stromal tumour & 01 & & \\
\hline & & f) Granulosa cell tumour & 01 & & \\
\hline & & g) Metastatic adenocarcinoma & 01 & & \\
\hline 10. & Uterus & Leiomyosarcoma & 01 & 01 & $2 \%$ \\
\hline \multirow{2}{*}{11.} & \multirow{2}{*}{ Testis } & a) Seminoma & 01 & \multirow{2}{*}{02} & \multirow{2}{*}{$4 \%$} \\
\hline & & b) Mixed germ cell tumour & 01 & & \\
\hline \multicolumn{4}{|c|}{ Total } & 50 & $100 \%$ \\
\hline
\end{tabular}

Out of 50 cases, the majority were ovarian neoplasms comprising of 21 (42\%) cases followed by thyroid (14\%), breast $(12 \%)$ and salivary gland (10\%) neoplasms (Table 2$)$.

Table-3: Diagnostic accuracy of imprint cytology in various organs

\begin{tabular}{|l|l|c|c|c|c|c|}
\hline \multirow{2}{*}{$\begin{array}{l}\text { So } \\
\text { No }\end{array}$} & \multirow{2}{*}{ Organs } & \multicolumn{2}{|c|}{ Correctly diagnosed cases } & \multicolumn{2}{|c|}{$\begin{array}{c}\text { False Negative(FN) / False } \\
\text { Positive(FP) }\end{array}$} & $\begin{array}{c}\text { Diagnostic } \\
\text { Accuracy }\end{array}$ \\
\cline { 3 - 6 } & & No. of cases & Percentage & No. of cases & Percentage & \\
\hline 1. & Brain & 03 & $06 \%$ & 00 & $00 \%$ & $100 \%(3 / 3)$ \\
\hline 2. & Pituitary gland & 01 & $02 \%$ & 00 & $00 \%$ & $100 \%(1 / 1)$ \\
\hline 3. & Salivary gland & 05 & $10 \%$ & 00 & $00 \%$ & $100 \%(5 / 5)$ \\
\hline 4. & Thyroid & 06 & $12 \%$ & $01[\mathrm{FN}]$ & $02 \%$ & $85.7 \%(6 / 7)$ \\
\hline 5. & Breast & 06 & $12 \%$ & 00 & $00 \%$ & $100 \%(6 / 6)$ \\
\hline 6. & Stomach & 01 & $02 \%$ & 00 & $00 \%$ & $100 \%(1 / 1)$ \\
\hline 7. & Lung & 01 & $02 \%$ & 00 & $00 \%$ & $100 \%(1 / 1)$ \\
\hline 8. & Pancreas & 02 & $04 \%$ & 00 & $00 \%$ & $100 \%(2 / 2)$ \\
\hline 9. & Ovary & 19 & $38 \%$ & $02[1-\mathrm{FP}, 1-\mathrm{FN}]$ & $04 \%$ & $90.5 \%(19 / 21)$ \\
\hline 10. & Uterus & 01 & $02 \%$ & 00 & $00 \%$ & $100 \%(1 / 1)$ \\
\hline 11. & Testis & 02 & $04 \%$ & 00 & $00 \%$ & $100 \%(2 / 2)$ \\
\hline & Total & $\mathbf{4 7}$ & $\mathbf{9 4 \%}$ & $\mathbf{0 3}$ & $\mathbf{0 6 \%}$ & $\mathbf{9 4 \%}(\mathbf{4 7 / 5 0 )}$ \\
\hline
\end{tabular}




\section{Original Research Article}

One case of ovarian neoplasm on imprint cytology was false positively reported as granulosa cell tumour as the imprint smears were cellular showing clusters of small, bland neoplastic cells occasionally arranged in small follicle-like structures and showing rare nuclear grooves (Figure 2A, 2B and 2C). But the frozen section revealed alternate hypercellular and hypocellular areas composed of dual population of cells (spindle shaped cells \& vacuolated cells) (Figure 2D and 2E). No nuclear grooves were noted. Therefore, a differential diagnosis of sclerosing stromal tumour and fibrothecoma was given. Finally, the histopathological examination showed cellular pseudolobules separated by thick fibrous bands (Figure 2F) and composed of two types of cells (spindle shaped cells and vacuolated cells resembling signet-ring cells). Also seen were many prominent thin-walled blood vessels and marked interlobular fibrosis. Thus, a diagnosis of sclerosing stromal tumour of ovary was given (Figure 1D).

In another ovarian neoplasm the imprint smears were cellular with many papillary structures showing stratification of the lining epithelium and nuclear atypia. Therefore, a diagnosis of borderline serous tumour was given false negatively. The frozen section revealed the foci of stromal invasion and so, a diagnosis of serous papillary cystadenocarcinoma was finally made which was concordant with the histopathological diagnosis. One case of micropapillary thyroid carcinoma was not diagnosed both by imprint cytology and frozen section because of gross sampling error in a case of adenomatoid goiter. Finally, on histopathological examination the focus of micropapillary carcinoma of thyroid was revealed.

Table-4: Diagnostic accuracy of frozen section in various organs

\begin{tabular}{|l|l|c|c|c|c|c|}
\hline \multirow{2}{*}{$\begin{array}{l}\text { SI. } \\
\text { No }\end{array}$} & \multirow{2}{*}{ Organs } & \multicolumn{2}{|c|}{ Correctly diagnosed cases } & \multicolumn{2}{c|}{$\begin{array}{c}\text { False negative (FN) / False } \\
\text { Positive (FP) }\end{array}$} & \multirow{2}{*}{$\begin{array}{c}\text { Diagnostic } \\
\text { Accuracy }\end{array}$} \\
\cline { 3 - 6 } & & No. of cases & Percentage & No. of cases & Percentage & \\
\hline 1. & Brain & 03 & $06 \%$ & 00 & $00 \%$ & $100 \%(3 / 3)$ \\
\hline 2. & Pituitary gland & 01 & $02 \%$ & 00 & $00 \%$ & $100 \%(1 / 1)$ \\
\hline 3. & Salivary gland & 05 & $10 \%$ & 00 & $00 \%$ & $100 \%(5 / 5)$ \\
\hline 4. & Thyroid & 06 & $12 \%$ & $01[F N]$ & $02 \%$ & $85.7 \%(6 / 7)$ \\
\hline 5. & Breast & 06 & $12 \%$ & 00 & $00 \%$ & $100 \%(6 / 6)$ \\
\hline 6. & Stomach & 01 & $02 \%$ & 00 & $00 \%$ & $100 \%(1 / 1)$ \\
\hline 7. & Lung & 01 & $02 \%$ & 00 & $00 \%$ & $100 \%(1 / 1)$ \\
\hline 8. & Pancreas & 02 & $04 \%$ & 00 & $00 \%$ & $100 \%(2 / 2)$ \\
\hline 9. & Ovary & 21 & $42 \%$ & 00 & $00 \%$ & $100 \%(21 / 21)$ \\
\hline 10. & Uterus & 01 & $02 \%$ & 00 & $00 \%$ & $100 \%(1 / 1)$ \\
\hline 11. & Testis & 02 & $04 \%$ & 00 & $00 \%$ & $100 \%(2 / 2)$ \\
\hline & Total & $\mathbf{4 9}$ & $\mathbf{9 8 \%}$ & $\mathbf{0 1}$ & $\mathbf{0 2 \%}$ & $\mathbf{9 8 \%}(\mathbf{4 9} / \mathbf{5 0})$ \\
\hline
\end{tabular}
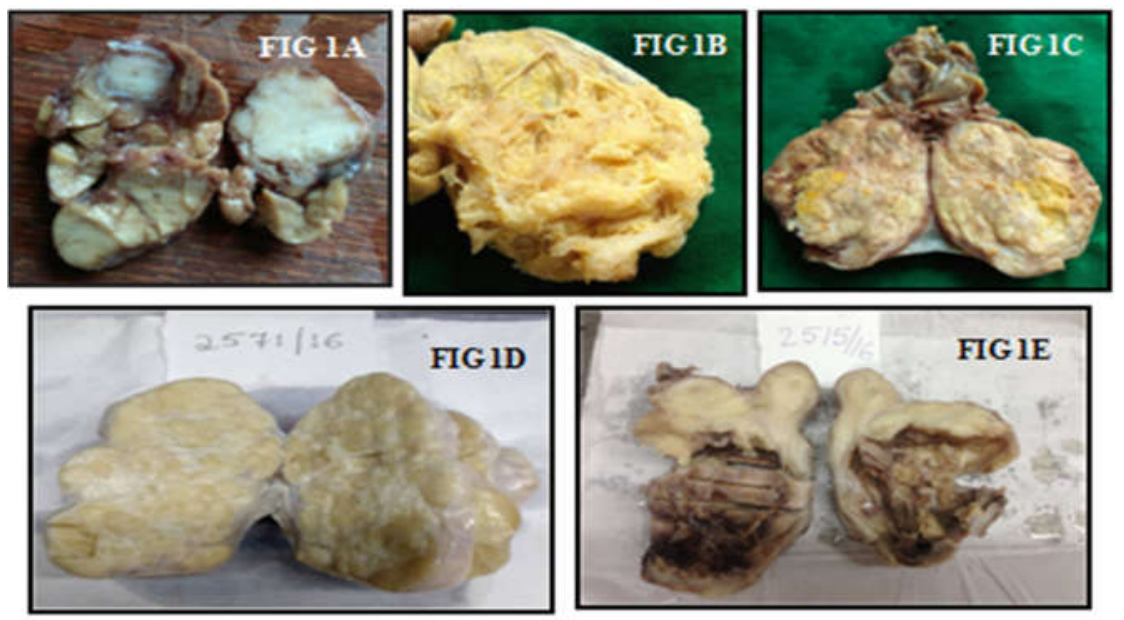

Figure-1: Gross specimens of Pleomorphic adenoma of salivary gland (1A), Serous papillary cystadenocarcinoma of ovary (1B), Seminoma of testis (1C), Sclerosing stromal tumour of ovary (1D), Leiomyosarcoma of uterus (1E). 


\section{Original Research Article}

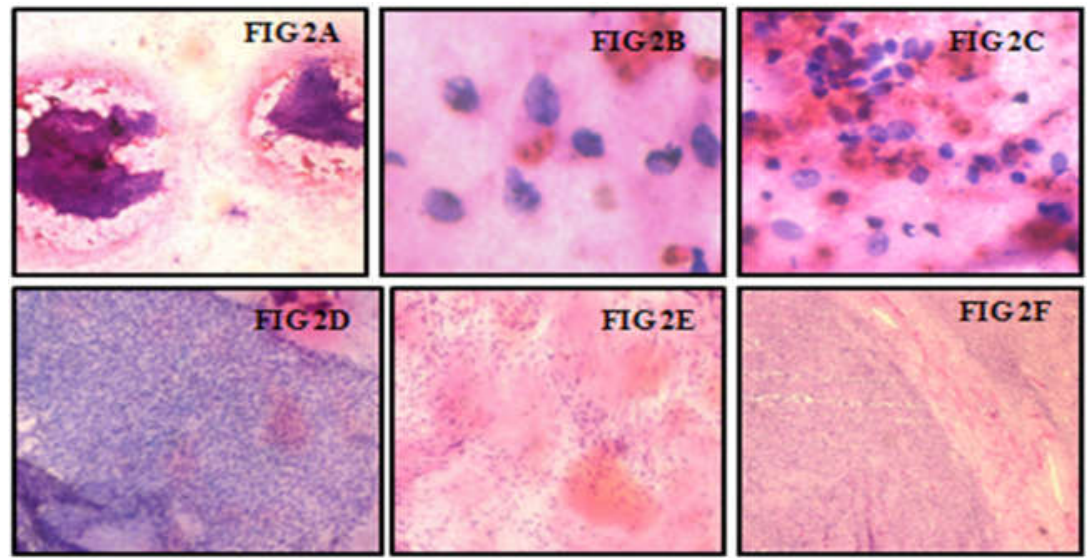

Figure-2: Imprint smears of sclerosing stromal tumour showing cellular smear (Figure 2A), occasional nuclear grooves (Figure 2B) andfollicle-like arrangement of cells (Figure 2C). Frozen section showing hypercellular area with spindle shaped cells (Figure 2D) and hypocellular area (Figure 2E) (x100, H and E). Paraffin section showing cellular pseudolobules separated by fibrous band (Figure 2F) (100X, Haematoxylin and Eosin).
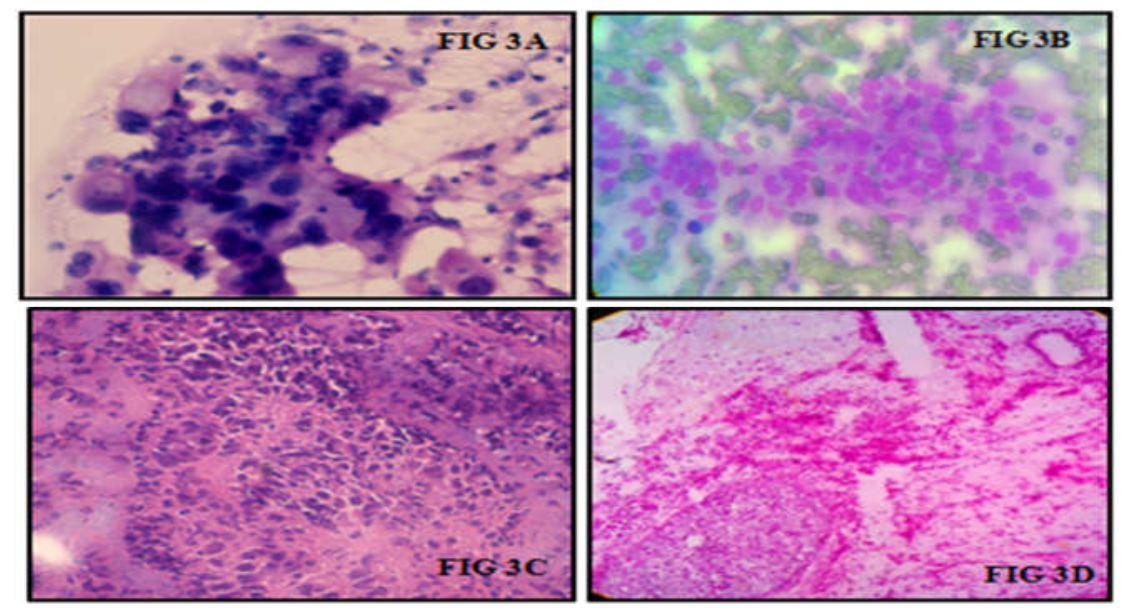

Figure-3A: Imprint smear showing marked anisonucleosis, chromatin clumping, nuclear overlapping and intracytoplasmic vacuoles in pancreatic adenocarcinoma (x400, Leishman's stain). Figure 3B: Imprint smear showing monomorphic cells in loose clustersand some arranged in small acini in pancreatic neuroendocrine carcinoma (x400, Leishman's stain). Figure 3C: Frozen section showing pleomorphic ductal epithelial cells in infiltrating ductal carcinoma of breast (x100, H \&E). Figure 3D: Frozen section showing focus of cartilage (in left lower corner) and embryonal component (in right upper corner) in mixed germ cell tumour of ovary (x100, H \& E).
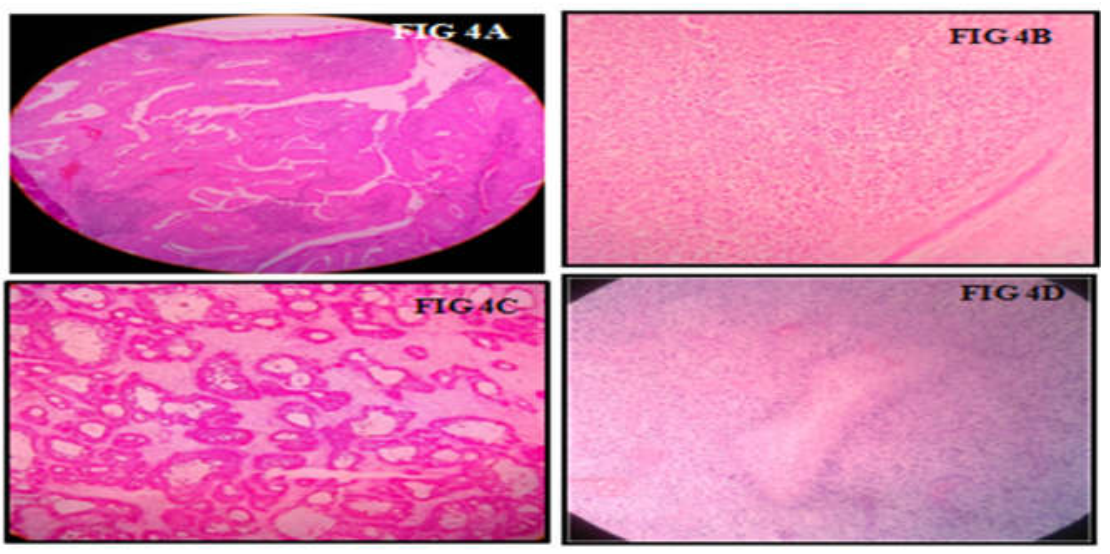

Figure-4: Histopathological sections of Warthin's tumour of salivary gland (Figure 4A), Seminoma of testis (Figure 4B), Metastatic deposits in ovary (Figure 4C) \& Glioblastoma multiforme (Figure 4D) (X100,H \& E). 

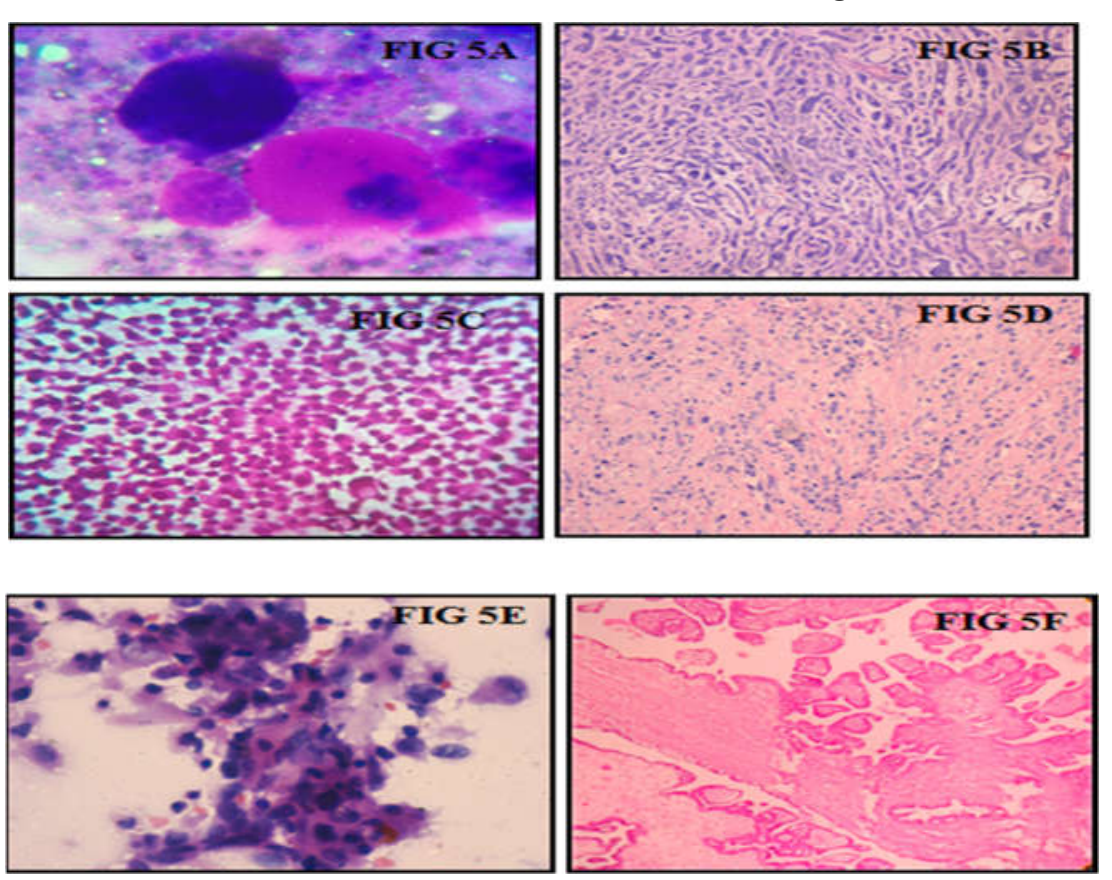

Figure-5: Imprint cytology smears and their corresponding histopathological tissue sections

Fig-5A: Imprint smear showing hyaline globules with adherent tumour cells in adenoid cystic carcinoma of salivary gland (X100, Leishman's stain) Fig 5B: Histopathology section showing cribriform, tubular and trabecular patterns in adenoid cystic carcinoma of salivary gland ( $x 40, H$ \& E). Fig 5C: Imprint smear showing discohesive and singly scattered plasmacytoid cells with intracytoplasmic lumina in infiltrating lobular carcinoma of breast (x100, H \& E). Fig 5D: Histopathology section showing linear pattern of loosely dispersed tumour cells amidst collagen fibres in infiltrating lobular carcinoma of breast (x100, H \& E). Fig 5E: Imprint smear showing papillary fragment with highly pleomorphic tumour cells and marked anisonucleosis in serous papillary cystadenocarcinoma of ovary (x100, Leishman's stain). Fig 5F: Histopathology section ofserous papillary cystadenocarcinoma of ovary showing stromal invasion (x100, H \& E).

\section{Discussion}

There are several studies in the literature which have confirmed the utility and efficacy of imprint cytology and frozen section as intraoperative consultation diagnostic modalities. These studieshave concluded that cytology has the advantage of being much less time consuming, easy to adopt, reliable and does not require special instruments [4,5]. Hence, imprintcytology can be employed routinely in the intraoperative diagnosis in conjunction with frozen section $[9,10]$. The use of either frozen section or cytological examination alone has an acceptable rate $(93-97 \%)$ of correct diagnosis, with regard to interpretation of benign versus malignant $[11,12,13]$.

The useof cytology smears during intraoperative consultation has often been neglected in favor of traditional examination of frozen sections. This appearsto be due to the surgical pathologist's relatively higher level of confidence in frozen sections, though many studies have demonstrated that the diagnostic efficacy of intraoperative cytology is comparable to that of frozen section [12].
In our study, a total of 50 surgically resected specimens were studied using both imprint cytology and frozen section. The diagnostic accuracy of imprint cytology and frozen section were evaluated individually by comparing with the gold standard histopathological examination. The diagnostic accuracy rates of imprint cytology is $80-97 \%$ in different studies [9, 14-20]. The diagnostic accuracy rates of imprint cytology and frozen section of our study was comparable with that of other studies and we obtained very good results.

Out of 50 cases, the ovarian neoplasms constituted the major group comprising of $21(42 \%)$ cases followed by thyroid (14\%), breast (12\%) and salivary gland $(10 \%)$ neoplasms. The diagnostic accuracy rates of imprint cytology and frozen section in ovarian neoplasms were $90.5 \%(19 / 21)$ and $100 \%$ respectively. The false negative and false positive rates of imprint cytology in ovarian neoplasms were $2 \%$ each. In a study conducted by Stewart et al., [8] 402 ovarian tumours were studied and all the benign ovarian lesions were accurately categorized using both imprint cytology and frozen 


\section{Original Research Article}

section. $30(86 \%)$ of borderline tumours and $137(97 \%)$ of malignant tumours were accurately diagnosed on frozen section whereas the corresponding results for cytology were $23(66 \%)$ and $131(93 \%)$ respectively. In a study by Abdel-Baset et al., [21] out of 60 ovarian masses, the overall accuracy of frozen section was $95.5 \%$. Out of $7(14 \%)$ thyroid cases in our study, one case of micropapillary thyroid carcinoma was not diagnosed both by imprint cytology and frozen section because of gross sampling error.

The diagnostic accuracy of both imprint cytology and frozen section in thyroid lesions was $85.7 \%(6 / 7)$. Sukumar Shaha et al., [22] studied a total of 57 thyroid lesions. The diagnostic accuracy of frozen and imprint cytology were $88.46 \%$ and $81.25 \%$ respectively. This was almost similar to our findings.

In the present study, the diagnostic accuracy of both imprint cytology and frozen section in breast tumours was $100 \%$. In a study conducted by Amar Ranjan et al [7] out of 31 cases of breast tumours all the cases were accurately categorized into benign, locally infiltrative and malignant tumours on frozen section.

Chandrakar J et al., [14] studied 36 breast lesions and imprint cytology correctly diagnosed $30(83.3 \%)$ cases and $6(16.66 \%)$ cases were unsatisfactory. In another study by Patil P et al., [19] the diagnostic accuracy of frozen section in breast lesions was $93.75 \%(15 / 16$ cases).

The diagnostic accuracy of both the techniques in other organs was $100 \%$ in the present study. Lee et al., [23] retrospectively studied 522 histologically proven tumours. The total diagnostic accuracy of imprint cytology was $92.9 \%$ for both benign and malignant tumours. Individually for benign tumours, accuracy rate was $97.2 \%$ and for malignant tumours it was $89.9 \%$.

In our study, all the three CNS cases were accurately diagnosed by frozen section and imprint cytology. SAM Ahmed et al., [24] studied 33 clinically diagnosed patients of CNS tumours. The sensitivity of frozen section was $100 \%$ and that of imprint was $75 \%$.

The accuracy of both the techniques were comparable in our study. The experience of the pathologist in interpretation of imprints is the mainstay in improving the diagnostic accuracy when both the techniques are combined [25].

Thus, a combination of these techniques plays a significant role in arriving at an accurate diagnosis rapidly and in guiding the surgeon intraoperatively in the management of patients.

\section{Conclusion}

Imprint cytology and frozen sections are interdependable intraoperative consultation diagnostic modalities. Imprint cytology alone may not be able to provide a correct diagnosis. Thus, a combination of imprint cytology and frozen section helps in achieving high diagnostic accuracy rates and in distinguishing benign and malignant lesions. They together form a very important aspect of surgical pathology that guide the surgeon's hand and play a significant role in rapid intraoperative pathological evaluation.

What does this study adds to existing knowledge: Many of the studies done in the past have either used imprint cytology or frozen section as an intraoperative diagnostic tool in arriving at a diagnosis. Only few of the studies have showed the combined role of imprint cytology and frozen section in intraoperative diagnosis. In our study, we have assessed the diagnostic accuracy rates of both the methods in various organs and also have evaluated their combined accuracy.

\section{Contribution Details}

SVD: Concepts, Design, Concepts, Data analysis, Manuscript review, Manuscript editing. AHN: Concepts, Design, Concepts, Data analysis, NC: Concepts, Design, Concepts, Data analysis, Manuscript review, Guarantor, BDS: Concept, Manuscript review, Guarantor

Funding: Nil, Conflict of interest: None initiated Permission from IRB: Yes

\section{References}

1. Dudgeon LS, Patrick CV. A new method for the rapid microscopical diagnosis of tumors: With an account of 200 cases so examined. $\mathrm{Br} \mathrm{J}$ Surg. 1927;15(58):250-61. DOI: https://doi.org/ 10.100.2/ bjs. 1800155810 .

2. Shahid M, Zaheer S, Mubeen A, Rahman K, Sherwani RK. The role of intraoperative cytology in the diagnostic evaluation of ovarian neoplasms. Acta Cytol.2012;56:467-73. DOI: https://doi.org/10.1159/ 000339394

3. Suen KC, Wood WS, Syed AA, et al. Role of imprint cytology in intraoperative diagnosis: value and limitations. J Clin Pathol. 1978 Apr;31(4):328-37.

4. Shidham VB, Dravid NV, Grover S, et al. Role of scrape cytology in rapid intraoperative diagnosis. Value and limitations. Acta Cytol. 1984 Jul-Aug; 28 (4): 477-82. 


\section{Original Research Article}

5. Gal R. Scrape cytology assessment of margins of lumpectomy specimens in breast cancer. Acta Cytol. 1988 Nov-Dec;32(6):838-9.

6. Kolte SS, Satarkar RN. Role of scrape cytology in the intraoperative diagnosis of tumor. J Cytol. 2010 Jul;27(3):86-90. doi: 10.4103/0970-9371.71871.

7. Ranjan A, Chandoke RK, Chauhan N, Rajkumari. Study of tumours by imprint cytology. IJCP. 2013;24(5):472-7.

8. Stewart CJR, Brennan BA, Koay E, Naran A, Ruba $S$. Value of cytology in the intraoperative assessment of ovarian tumors: A review of 402 cases and comparison with frozen section diagnosis. Cancer cytopathol. 2010; 118(3):127-36. DOI: http://dx.doi.org/10. 1002/ cncy.20073.

9. Esteban $\mathrm{JM}^{1}$, Zaloudek C, Silverberg SG. Intraoperative diagnosis of breast lesions. Comparison of cytologic with frozen section technics. Am J Clin Pathol. 1987 Dec;88(6):681-8.

10. Mair S, Lash RH, Suskin D, et al. Intraoperative surgical specimen evaluation: frozen section analysis, cytologic examination, or both? A comparative study of 206 cases. Am J Clin Pathol. 1991 Jul;96(1):8-14.

11. Scucchi LF, Di Stefano D, Cosentino L, Vecchione A. Value of cytology as an adjunctive intraoperative diagnostic method. Acta Cytol. 1997;41(5):1489-96. DOI: https://doi.org/10.1159/000332864.

12. Shidham V, Gupta D, Galindo LM, et al. Intraoperative scrape cytology: comparison with frozen sections, using receiver operating characteristic (ROC) curve. Diagn Cytopathol. 2000 Aug;23(2):134-9.

13. Tribe CR. A comparison of rapid methods including imprint cytodiagnosis for the diagnosis of breast tumors. J Clin Path. 1973;26(4):273-7.

14. Chandrakar J, Srivastava S. Evaluation of the relevance of touch imprint cytology in the diagnosis of various neoplastic lesions. Int $\mathrm{J}$ Res Med Sci. 2015;3(11):3046-50. DOI: https://dx.doi.org/ 10.18203/ 2320-6012.ijrms20150920.

15. Mehar R, Panchonia A, Kulkarni CV. Study of imprint smears of various lesions with histological correlation. Int J Med Sci Public Health.2014;3(4):486-8.
16. Chandramouleeswari K, Yogambal M, Arunalatha P, Bose JC, Rajendran A. Frozen and paraffin sectionsComparative study highlighting the concordance and discordance rates in a tertiary care centre. IOSR Journal of Dental and Medical Sciences (IOSR-JDMS). 2013;12(5): 26-30.

17. Agarwal P, Gupta S, Singh K, Sonkar AA, Rani P, Yadav S, Goel MM. Intra-Operative frozen sections: Experience at a tertiary care centre. Asian Pac J Cancer Prev. 2016;17(12): 5057-61.DOI: https://doi.org/10. 22034/ APJCP.2016.17.12.5057.

18. Shrestha S, Lee MC, Dhakal H, Pun CB, Pradhan M, Shrestha S, Basyal R, Pathak T. Comparative Study of frozen section diagnoses with histopathology. PMJN. 2009;9(2):1-3.

19. Patil P, Shukla S, Bhake A, Hiwale K. Accuracy of frozen section analysis in correlation with surgical pathology diagnosis. Int J Res Med Sci. 2015;3 (2):399404. DOI: https://doi.org/10.5455/2320-6012.ijrms 20150203 .

20. Ahmad Z, Barakzai MA, Idrees R, et al. Correlation of intra-operative frozen section consultation with the final diagnosis at a referral center in Karachi, Pakistan. Indian J Pathol Microbiol. 2008 Oct-Dec;51(4):469-73.

21. Mohammed ABF, Ahuja VK, Farghaly H. Role of frozen section in the intraoperative management of ovarian masses.Middle East Fertil Soc J. 2015;20 (2): 97-101. DOI: https://doi. org/10.1016/j. mefs. 2014. 06. 001.

22. Shaha S, Nahar Rahman AJE. Comparative study of imprint cytology and frozen section in the intraoperative diagnosis of thyroid lesions. Bangladesh J Pathol. 2009;24(1):12-5.

23. Lee TK. The value of imprint cytology in tumor diagnosis: a retrospective study of 522 cases in northern China. Acta Cytol. 1982 Mar-Apr;26(2):169-71.

24. Ahmed SAM, Badruddoza SM, Meherunnesa, Ekramullah SM, Hossain MZ, Habib A, et al. Diagnostic accuracy of imprint cytology and frozen section for CNS tumor. Faridpur Med Coll J. 2014;9 (1):24-7.

25. Khalid A, Haque AU. Touch impression cytology versus frozen section as intraoperative consultation diagnosis. Int J Pathol. 2004;2(2):63-70.

\section{How to cite this article?}

Shubha. H.V., Arun. H.N., Nirmala. C., Dayananda B.S. Role of imprint cytology and frozen section in the diagnosis of tumours. Trop J Path Micro 2018;4(8):578-585.doi:10.17511/jopm.2018.i08.06. 